\author{
Cadernos de \\ ESTUDOS LINGUÍSTICOS - (58.3), Campinas, pp. 481-501 - set./dez. 2016
}

\title{
A SOCIOLINGUÍSTICA LABOVIANA: FESTEJANDO O CINQUENTENÁRIO E PLANEJANDO O FUTURO
}

\author{
JOSANE MOREIRA DE OLIVEIRA ${ }^{1}$
}

\begin{abstract}
RESUMO: Neste artigo apresenta-se um breve balanço da área de estudos sociolinguísticos no Brasil a partir da publicação da obra seminal de William Labov, The Social Stratification of English in New York City, em 1966. Considerando que essa tese de Labov lançou as sementes de um profícuo campo de estudos que encontrou terreno fértil para florescer no Brasil, lança-se um olhar simultâneo para o passado, o presente e o futuro, apontando o que já foi feito nestes últimos cinquenta anos e o que ainda é preciso fazer/aperfeiçoar no que tange às questões fundamentais propostas pela Teoria da Variação e da Mudança Linguística. Além de mencionar alguns dos muitos e incontáveis trabalhos sociolinguísticos realizados no País, em vários níveis de estruturação da língua, destacando o crescimento da área em solo brasílico, exemplifica-se a aplicação do quadro teórico-metodológico da sociolinguística variacionista com pesquisas próprias: o apagamento do /R/ em coda silábica (OLIVEIRA 1999); a variação na expressão do futuro verbal (OLIVEIRA 2006); a palatalização de /t, d/ diante de [i] (OLIVEIRA; MOTA a sair); a variação na expressão do imperativo gramatical (OLIVEIRA a sair). Finalmente, sugerem-se caminhos a serem percorridos nos próximos cinquenta anos para o mapeamento e a descrição sociolinguística do português brasileiro.
\end{abstract}

Palavras-chave: Sociolinguística laboviana. Português brasileiro. Pesquisas variacionistas.

RÉSUMÉ : Nous présentons dans cet article un petit panorama des recherches sociolinguistiques au Brésil à partir de l'oeuvre séminale de William Labov, The Social Stratification of English in New York City, parue en 1966. En considérant que cette thèse de Labov a planté les graines d'un champ important d'études qui a trouvé un terrain fertile pour fleurir au Brésil, nous regarderons simultanément le passé, le présent et le futur pour relever ce qui a été déjà réalisé au cours des cinquante dernières années et ce qui doit être encore réalisé/perfectionné en ce qui concerne les questions fondamentales proposées par la Théorie de la Variation et du Changement Linguistique. Au-délà des références faites à certains des innombrables travaux sociolinguistiques menés au Brésil, sur plusieus niveaux de structuration de la langue, mettant en exergue la croissance nationale de ce domaine de recherche, nous exemplifierons l'application du cadre théorique-méthodologique de la sociolinguistique variationnelle à partir de recherches personnelles : l'effacement du /R/ en coda syllabique (OLIVEIRA 1999); la variation dans l'expression du futur verbal (OLIVEIRA 2006); la palatalisation de /t, $\mathrm{d} /$ devant [i] (OLIVEIRA ; MOTA à paraître); la variation dans l'expression de l'impératif grammatical (OLIVEIRA à paraître). Nous montrerons enfin des chemins à suivre pour les cinquante ans à venir en cartographie et en description sociolinguistique du portugais brésilien.

Mots-Clés : Sociolinguistique labovienne. Portugais brésilien. Recherches variationnistes.

\footnotetext{
${ }^{1}$ Universidade Estadual de Feira de Santana / Universidade Federal da Bahia / CAPES.
} 


\section{INTRODUÇÃO}

Há exatos cinquenta anos, em 1966, William Labov presenteou a comunidade de linguistas com sua obra The Social Stratification of English in New York City (SSENYC), em essência a sua tese de Doutorado, realizada sob a direção de Uriel Weinreich e defendida em 1964 na Columbia University. Passados quarenta anos, em 2006, a Cambridge University Press publicou a segunda edição do livro, revista e ampliada pelo próprio autor.

Essa obra seminal, festejando agora seu cinquentenário, mantém-se como a grande base e referência mundial dos estudos sociolinguísticos, juntamente com o clássico texto Empirical Foundations for a Theory of Language Change, de Uriel Weinreich, William Labov e Marvin Herzog, apresentado no Simpósio "Direções para a Linguística Histórica" (Universidade do Texas, 1968), publicado pela University of Texas Press em 1975 e traduzido para o português em 2006. Nela estão os fundamentos da Teoria da Variação e da Mudança Linguística, conhecida também como Sociolinguística Variacionista, que tem como pressuposto a análise das relações entre linguagem e sociedade e que se tornou um campo fértil para o estudo da língua em seu contexto social desde então.

Embora tenha descrito a fala da comunidade de um grande centro urbano (a cidade de Nova Iorque), mostrando a estratificação social e estilística da variação fônica no inglês, incluindo a análise das reações subjetivas a essa variação - áreas consideradas inacessíveis para a linguística formal -, Labov estabelece nessa obra princípios, conceitos e métodos utilizados até hoje nas diversas pesquisas sociolinguísticas - que continuam a ela remetendo -, muitos dos quais foram retomados em obras posteriores (LABOV 1972, 1994, 2001, 2010).

São conceitos básicos nos estudos de variação e mudança assentados no SSENYC: variável linguística, estratificação social, estratificação estilística, padrão curvilíneo, tempo aparente, prestígio. Quanto aos procedimentos metodológicos para os estudos sociolinguísticos, o SSENYC apresenta: a constituição da amostra, a entrevista e o controle do estilo, testes de reação subjetiva, relato pessoal e testes de insegurança linguística. Assim, o SSENYC instaura definitivamente uma nova forma de estudar a língua em uso, unindo três grandes áreas do conhecimento: linguística, sociologia e antropologia.

Nestes cinquenta anos, muitos foram os trabalhos realizados com base no aporte teórico-metodológico laboviano, dentre os quais se destaca a gama de pesquisas sociolinguísticas desenvolvidas no Brasil a partir da década de 1970, quando Anthony Julius Naro começou a formar os primeiros pesquisadores na Teoria da Variação e da Mudança na cidade do Rio de Janeiro (VOTRE; RONCARATI 2008).

\section{UM OLHAR PARA O PASSADO}

O SSENYC apresentou ao mundo algumas questões centrais para o campo dos estudos sociolinguísticos: o estudo da língua em seu contexto social, a diferenciação social das variáveis e a sua distribuição no tempo aparente, e a avaliação social das variáveis. 
Cadernos de ESTUDOS LINGUÍSTICOS (58.3) - set./dez. 2016

A partir de então, começaram a ser criados os primeiros projetos e grupos de pesquisa brasileiros, com o objetivo de constituir bancos de dados para posterior análise sociolinguística: NURC - Projeto de Estudo da Norma Urbana Culta do Brasil (1969), Competências Básicas do Português (1977), PEUL Programa de Estudos dos Usos da Língua (1980), Confluência Dialetal na Nova Capital Brasileira (1984), VARSUL - Variação Linguística Urbana da Região Sul (1989), VALPB - Variação Linguística na Paraíba (1994), Dialetos Sociais Cearenses (1996), LUAL - A Língua Usada em Alagoas (1997). E citam-se aqui apenas os pioneiros, pois muitos outros projetos começaram a ser desenvolvidos em todo o País.

Segundo Mollica e Roncarati (2001:46),

a maioria dos pesquisadores nessa área hoje congrega-se em Projetos Integrados, formando polos de atuação que permitem estabelecer uma rede complementar de resultados, referendando-os ou contestando-os. Ao adotar perspectivas diferentemente priorizadas, em grupo ou isoladamente, os estudiosos recobrem um painel de conhecimentos sobre as dimensões geodialetal, sócio-estratificada, histórico-social e discursivo-cultural.

Os primeiros trabalhos na área da sociolinguística realizados no Brasil versaram sobre: concordância nominal (BRAGA 1977; SCHERRE 1978; SCHERRE 1988; LUCCHESI 2000); construções relativas (MOLLICA 1977); derivação sufixal (MONTALVO 1978); segmentos nasal e vibrante em final de vocábulos (VOTRE 1978); pronome pessoal de terceira pessoa em função acusativa (OMENA 1978); distribuição da vibrante (CALLOU 1979); segmentos africados e fricativos (PALMA 1980); pronomes pessoais e oblíquos átonos (DEL-GÁUDIO 1981); pronomes átonos (PEREIRA 1981); harmonização vocálica (BISOL 1981); futuro do subjuntivo (MACEDO 1981); possessivos (OLIVEIRA E SILVA 1983); flexão do infinitivo (LADEIRA 1986); expressão do sujeito (PAREDES SILVA 1988); queísmo e dequeísmo (MOLLICA 1989); orações condicionais (GRYNER 1990); verbos existenciais (FIORETTI 1996); regência do verbo ir (RIBEIRO 1996); variação entre tudo e todo (PINTO 1996). E citam-se aqui apenas as primeiras dissertações e teses produzidas no Rio de Janeiro sob a orientação do pioneiro Anthony Naro (VOTRE; RONCARATI 2008:21-36).

Muitos outros trabalhos, além dos citados, também foram realizados ao longo destes cinquenta anos, cunhando no Brasil a tradição de estudos sociolinguísticos, retomando os temas anteriormente referidos e ampliando a gama de temas explorados, que se exemplificam a seguir: vogais pretônicas (VIEGAS 1987; SILVA 1989; YACOVENCO 1993; PEREIRA 1997; SOARES 2004; KAILER 2008; SILVA 2009; VOGELEY 2011); vogais postônicas (SANTOS 2010); ditongos (CABREIRA 1996; SILVA 1997; LOPES 2002); palatalização de consoantes (HORA 1990; RAMOS 1999; CARVALHO 2002; ANDRADE 2008; MARTINS 2008); lateral em coda silábica (SÁ 2007; MOURA 2009); /S/ em coda silábica (OLIVEIRA 2001; RODRIGUES 2001; SARAIVA 2001; MACEDO 2004; RIBEIRO 2006); concordância verbal (RODRIGUES 1988; AMARAL 2003; CARDOSO 2005; SILVA, S. 2005; SILVA, J. 2005; MONGUILHOTT 2009; ALMEIDA 2010; RUBIO 2012; ARAÚJO 2014; OUSHIRO 2015); imperativo gramatical 
OLIVEIRA - A sociolinguística laboviana: festejando o cinquentenário e planejando o futuro

(SAMPAIO 2001; LIMA 2005; JESUS 2006; CARDOSO 2009; EVANGELISTA 2009; ROST-SNICHELOTTO 2009); futuro verbal (SANTOS 1997; GIBBON 2000; SANTOS 2000; MALVAR 2003; OLIVEIRA 2006; ALMEIDA SANTOS 2008; BRAGANÇA 2008; SILVA 2010; ALVES 2011; TESCH 2011; SANTOS 2012; ALMEIDA 2015; FIGUEREIDO 2015); futuro do pretérito (COSTA 1997; COSTA 2003; BARBOSA 2005; SANTOS 2014); passado verbal (FREITAG 2007); modos indicativo/subjuntivo (ROCHA 1997; CARVALHO 2007; BARBOSA 2011; PIMPÃO 2012); pronomes $t u$ e você (RAMOS 1989; LUCCA 2005; ANDRADE 2010; MARTINS 2010; CARNEIRO 2011; FRANCESCHINI 2011; ROCHA2012); pronomes nós e a gente (FERNANDES 1997; FERREIRA 2002; FRANCESCHINI 2011; VIANNA 2011); colocação pronominal (VIEIRA 2002; MACHADO 2006); pronomes possessivos (ANDRADE NETA 2003; ARDUIN 2005; LUCENA 2016); indeterminação do sujeito (CUNHA 1993; MENON 1994; SETTI 1998; GODOY 1999; ASSUNÇÃO 2012; SOUZA 2014); objeto direto (MALVAR 1992; MENDONÇA 2002; FIGUEIREDO SILVA 2004; MARAFONI 2004; SILVA 2008; MARAFONI 2010); preposições (FELGUEIRAS 1993; GOMES 1997; LUCENA 2001; VALHO 2003; TAMBA 2010; SOUZA 2015); artigos (BATISTA 1996; AMARAL 2003; NAZÁRIO 2007; NASCIMENTO 2008); ordem (ALMEIDA 1998; SPANÓ 2008); interrogativas (OUSHIRO 2011); negação (SOARES 2009); dentre muitos outros e para exemplificar apenas com dissertações de Mestrado e teses de Doutorado defendidas.

Ressalte-se que a lista apresentada está muito longe de ser exaustiva e não engloba os inúmeros artigos, capítulos de livros e livros com análises sociolinguísticas sobre os vários temas. $\mathrm{O}$ que se quer mostrar é que muito se fez nestes cinquenta anos. Acrescentem-se a isso as inúmeras monografias de conclusão de curso de graduação e de pós-graduação lato sensu por todo o País. Em suma, realizar um levantamento exaustivo para um balanço mais ou menos exato da produção na área é uma tarefa humanamente impossível.

Enfim, pode-se mesmo dizer que milhares de produtos foram gerados na área neste meio século, em todos os rincões brasileiros e em todos os níveis linguísticos, no âmbito da descrição, no âmbito da discussão de pontos teóricos e no âmbito do debate acerca do preconceito linguístico e do ensino de Língua Portuguesa, como bem já mostraram Paiva e Scherre (1999), Paiva e Duarte (2006) e Salomão (2011). Segundo Paiva e Scherre (1999:203), essa diversidade de estudos sociolinguísticos no Brasil "tem possibilitado acúmulo considerável de conhecimento acerca da multidialetação diatópica e diastrática, da sistematicidade do uso linguístico e dos processos de mudança na variedade brasileira do português".

\section{UM OLHAR PARA O PRESENTE}

Acrescentando outros dados ao panorama aqui traçado da Sociolinguística no Brasil, cumpre informar que dos 59 cursos de pós-graduação stricto sensu em Linguística atualmente em funcionamento no Brasil, a maioria tem linha de pesquisa na área de Sociolinguística, gerando mais de uma centena de dissertações e teses anualmente. 
Cadernos de ESTUDOS LINGUífTICOS (58.3) - set./dez. 2016

Mais uma evidência da fertilidade dessa área no Brasil é o Grupo de Trabalho (GT) de Sociolinguística da Associação Nacional de Pós-Graduação em Letras e Linguística (ANPOLL), que conta hoje com cerca de oitenta associados e que se subdivide em quatro eixos: 1. Descrição e Mapeamento Sociolinguístico do Português Brasileiro; 2. Contato, Variação e Identidade; 3. Sociolinguística e Ensino; e 4. Interfaces Teórico-Metodológicas. O GT, que se reúne anualmente, segue uma agenda de trabalho e discute resultados de pesquisas na área, além de organizar também publicações.

Consultando o Diretório dos Grupos de Pesquisa do Conselho Nacional de Pesquisa (CNPq), Salomão (2011) constata a existência de 48 grupos, distribuídos por todas as regiões do Brasil,

que pesquisam a língua(gem) por meio dos pressupostos da teoria da variação e mudança, muitas vezes alinhada a outras teorias, como o funcionalismo e o gerativismo. Há ainda grupos interdisciplinares que aliam a sociolinguística variacionista às teorias da tradução e aos estudos de fonologia clínica e aquisição de linguagem [...] (SALOMÃO 2011:201)

Merecem ser mencionados também os vários eventos na área (encontros, seminários, simpósios, congressos), que acontecem em várias cidades brasileiras, sejam os específicos (Encontro de Sociolinguística da UNEB/UEFS/UFS/UFMG/ UFOP, Encontro Nacional de Sociolinguística da UFES, Seminário de Variação Linguística da UESB, por exemplo), sejam os mais gerais, em que sempre há conferências, mesas-redondas, simpósios temáticos e/ou sessões temáticas na área (Congresso da Associação Brasileira de Linguística - ABRALIN), aos quais deve-se acrescentar o Congresso Internacional de Dialetologia e Sociolinguística - CIDS, que teve em 2016, em Paris, a sua quarta edição, homenageando pesquisadores da área do Brasil e do Exterior, dentre os quais Anthony Julius Naro.

Nota-se também a presença de cada vez mais pesquisadores brasileiros nos grandes congressos internacionais organizados fora do Brasil, como, por exemplo, o NWAV (New Ways on Analysing Variation), o Sociolinguistics Symposium e o Colloque Variation Diasystématique dans les Langues Romanes (DIA), nos quais se observa também o aumento do número de pesquisadores estrangeiros que tomam como objeto de análise o português brasileiro.

Cumpre registrar, com destaque, que o próprio Atlas Linguístico do Brasil (ALiB) - projeto em andamento, mas com os dois primeiros volumes já publicados (CARDOSO et al. 2014a, 2014b), os dois próximos no prelo e os demais em processo de gestação - é um atlas geossociolinguístico, tendo, dentre outros, o objetivo de "contribuir para o entendimento da língua portuguesa no Brasil como instrumento social de comunicação diversificado, possuidor de várias normas de uso, mas dotado de uma unidade sistêmica" (http://www.alib.ufba.br/content/objetivos). O ALiB documentou o português falado no Brasil do Oiapoque ao Chuí, numa rede de 250 localidades (aí incluídas as capitais de Estado, com exceção de Brasília e Palmas, pelo seu pouco tempo de formação), inquirindo 1.100 informantes (estratificados por sexo, faixa etária e escolaridade) e perfazendo um total de cerca de 3.300 horas de gravação. Os inquéritos envolvem um questionário fonético-fonológico (aí incluídas questões de prosódia), um questionário semântico-lexical, um questionário morfossintático, questões de pragmática, discursos semidirigidos, perguntas metalinguísticas e um texto para leitura. Esse robusto banco de dados tem servido de material para análises dialetológicas e também sociolinguísticas por todo o País. 
E inúmeros bancos de dados estão organizados ou em organização/ampliação em muitas universidades brasileiras, sob a responsabilidade de vários grupos/ núcleos de pesquisa que começaram a se constituir desde a década de 1970 e que vêm agregando cada vez mais pesquisadores que se debruçam sobre análises de dados orais e escritos do português do ponto de vista variacionista.

Esse campo de pesquisa tem se ampliado inclusive por áreas interdisciplinares, tais como a Sociolinguística Educacional, a Sociolinguística Interacional, a Sociolinguística Paramétrica, a Etnolinguística, o SócioFuncionalismo, a Sócio-História do Português Brasileiro, o Contato Dialetal, a Política Linguística, além de trabalhos que comparam, sociolinguisticamente, o português do Brasil com outras variedades, como a lusitana, a angolana, a moçambicana, a guineense, a são-tomeense etc., e de trabalhos que comparam o português com outras línguas, em estudos translinguísticos. Ou seja, está explicado o fato de o próprio Labov ter relatado a Anthony Naro a sua admiração pela Sociolinguística brasileira. E, segundo Carboni (2008 apud SALOMÃO 2011:192-193), a sociolinguística laboviana predomina hoje sobretudo nas Américas do Sul e do Norte, regiões onde tende a ser considerada como a Sociolinguística propriamente dita.

Nas próximas subseções, são apresentadas brevemente pesquisas autorais no campo da sociolinguística laboviana, como exemplos da apropriação do aporte teórico-metodológico instaurado com a publicação do SSENYC. Assim, seguem resumos de pesquisa sobre o apagamento do /R/ em coda silábica, sobre a expressão variável do futuro verbal, sobre a palatalização de /t, d/ diante de [i] e sobre a expressão variável do imperativo gramatical.

\subsection{O apagamento do /R/ em coda silábica}

Em dissertação de Mestrado, Oliveira (1999) trabalhou com trinta e dois inquéritos do Projeto NURC, todos da cidade de Salvador, distribuídos por dois tipos de texto (menos formal - Diálogos entre informante e documentador e mais formal - Elocuções formais), dois sexos (masculino e feminino) e três faixas etárias ( 25 a 35 anos, 36 a 55 anos e 56 anos em diante), com o intuito de verificar o apagamento do / $\mathrm{R} /$ implosivo na língua falada, que pode ocorrer tanto em posição medial (universo/unive[Ø]so, cerveja/ce[Ø]veja) como em posição final

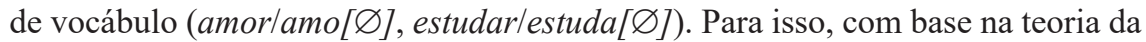
Sociolinguística Variacionista, foram considerados fatores internos (linguísticos) e externos (sociolinguísticos) que pudessem condicionar a variável realização ou apagamento do fonema em questão.

A análise revelou que, na fala culta de Salvador, de acordo com os dados examinados (da década de 1970), prevalece a manutenção do /R/ implosivo em posição medial de palavra (93\% nas EFs e $90 \%$ nos DIDs), embora ele tenha sofrido apócope resultante de um processo de simplificação silábica em alguns dados. $\mathrm{O}$ apagamento é mais frequente em posição final de vocábulo (60\% nas EFs, com peso relativo - P.R. - de 0,94, e 82\% nos DIDs, com peso relativo de 0,93), mas já é documentado também em posição medial (7\% nas EFs e 10\% nos DIDs). 
Cadernos de ESTUDOS LINGUísTICOS (58.3) - set./dez. 2016

Esse processo mostrou-se condicionado à sucessão de uma consoante constritiva (/s/, /v/) - com a qual o /R/ comunga o mesmo modo de articulação (pesos relativos de 0,53 e 0,71 nas EFs e nos DIDs, respectivamente), já que, quando realizado, foi articulado como uma constritiva velar - e à precedência da vogal /u/, com a qual se assemelha quanto à zona de articulação (pesos relativos de 0,86 e 0,69 nas EFs e nos DIDs, respectivamente). Trata-se, pois, de um processo assimilatório.

A sílaba pretônica foi a que mais favoreceu o apagamento (em posição medial de palavra) - pesos relativos de 0,62 e 0,64 nas EFs e nos DIDs, respectivamente -, seguida pela sílaba tônica dos infinitivos verbais (em posição final de palavra) pesos relativos de 0,58 e 0,66 nas EFs e nos DIDs, respectivamente. Foram os verbos e as conjunções - sobretudo porque e portanto - as classes de palavras em que o processo atuou com mais aplicação. No caso dos verbos, o /R/ sofreu apagamento em $66 \%$ dos dados das EFs e em 89\% dos dados dos DIDs. No caso das conjunções, foi apagado em 35\% e 55\% dos dados das EFs e dos DIDs, respectivamente. O /R/ do infinitivo verbal torna-se redundante e a marca morfológica - com a supressão do fonema - passa a ser a tonicidade da sílaba (os verbos no infinitivo são oxítonos) e o contexto sintático, além de um leve alongamento da vogal temática final.

O sexo/gênero masculino foi o que mais suprimiu o /R/ (peso relativo de 0,53), embora não tenha havido uma diferença significativa entre a fala dos homens e a das mulheres (estas apresentaram peso relativo de 0,49). Independentemente do sexo do falante, esse processo de apagamento está em franca expansão na fala culta de Salvador.

$\mathrm{O}$ apagamento do $/ \mathrm{R} /$ implosivo foi documentado tanto em registros formais ( $32 \%$ dos dados) como em registros informais ( $46 \%$ dos dados), sendo estes últimos, ainda que timidamente, os que apresentaram maior favorecimento dessa variante.

Trata-se de um processo de mudança em progresso, pois as faixas etárias mais jovens realizaram mais a variante inovadora (apagamento) do que as faixas mais avançadas de idade. A análise, considerando o aparato do tempo aparente, mostrou um decréscimo do cancelamento à medida que aumenta a idade dos informantes (com os seguintes pesos relativos: Faixa 1 - 0,59; Faixa 2 - 0,52; Faixa $3-0,47$; Faixa $4-0,34)$.

\subsection{A variação na expressão do futuro verbal}

Em tese de Doutorado, Oliveira (2006) analisou a variação na expressão do futuro verbal em português, do ponto de vista diacrônico (do século XIII ao XX). No estudo de tendência (anos 1970 e anos 1990 do século XX), foram consideradas as modalidades escrita (editoriais de jornais) e falada (dados de entrevistas sociolinguísticas do Projeto NURC) da língua, com a comparação de dados das cidades de Salvador e do Rio de Janeiro.

Os dados são todos representativos de um nível ou estilo linguístico culto (documentos e cartas formais ou editoriais de jornais para a escrita e entrevistas com informantes de nível superior completo para a fala). Essa variação apresenta seis variantes: a) o futuro simples (viajarei amanhã); b) o presente (viajo amanhã); c) a perífrase com ir no presente + infinitivo (vou viajar amanhã); d) a perífrase com ir no futuro + infinitivo (irei viajar amanhã); e) a perífrase com haver de no presente + infinitivo (hei de viajar amanhã); e f) a perífrase com haver de no futuro + infinitivo (haverei de viajar amanhã). 
Tomando como base teórica a Sociolinguística Variacionista e princípios do paradigma da gramaticalização, a análise dos dados revelou que: a) o futuro simples se mantém mais ou menos estabilizado ao longo do tempo na língua escrita formal, em que ainda é a forma preferida (seu uso, entretanto, varia: 54,5\% no século XIII; 91,9\% no século XIV; $81,3 \%$ no século XV; $87,4 \%$ no século XVI; 74,4\% no século XVII; $83,3 \%$ no século XVIII; $85,8 \%$ no século XIX; e $75,3 \%$ no século $\mathrm{XX})$; b) o presente é mais usado na língua falada (91\%) do que na língua escrita (9\%) e se mantém historicamente em contextos bem específicos (para expressar um futuro próximo e com a presença de um elemento adverbial de tempo); c) as perífrases com haver de + infinitivo decrescem em uso através dos séculos (de 45,5\% no século XIII para 1,9\% no século XX), deixando de ser (no século $\mathrm{XX}$ ) a principal concorrente do futuro simples e recuperando o seu traço deôntico; d) as perífrases com ir + infinitivo invadem cada vez mais a língua escrita (alcançando cerca de 30\% dos dados na escrita jornalística do século XX), e chegam mesmo a superar o futuro simples na língua falada $(98 \%$ dos dados no século XX) (OLIVEIRA; MENON 2015); e) evidencia-se um processo de gramaticalização do verbo $i r$, que passa de pleno a auxiliar na composição da forma perifrástica com o infinitivo para expressar o futuro.

O fenômeno estudado não é exclusivo da língua portuguesa; é também documentado em muitas outras línguas (e não só românicas), como o inglês, o francês, o espanhol, o italiano, o romeno e o sardo, o que, aliás, comprova que as línguas SVO preferem formas perifrásticas a formas sintéticas. Pode-se defender uma mudança em andamento, a saber, a substituição do futuro simples pelo futuro perifrástico; é o que revela o estudo em tempo real de curta duração do tipo tendência feito com dados do século XX.

Um excelente exemplo da relação entre variação/mudança linguística e variação/ mudança social é apresentado quando da explicação do fato de a comunidade de Salvador, considerada mais conservadora nos anos 1970 (65\% dos dados foram de futuro perifrástico) em relação ao Rio de Janeiro (89\% dos dados foram de futuro perifrástico), ter sido categórica na aplicação da regra da variante inovadora (futuro perifrástico) nos anos 1990, não tendo apresentado nenhuma ocorrência da variante conservadora (futuro simples) e tendo superado a comunidade do Rio de Janeiro, que apresentou ainda 5\% de dados de futuro simples. A partir de dados sócio-demográficos, a autora apresenta a mudança social ocorrida na cidade de Salvador nesse intervalo de vinte anos (crescimento populacional, aumento das taxas de alfabetização e do índice de desenvolvimento humano, modernização e urbanização da cidade, implantação do polo industrial, do polo petroquímico e de grandes fábricas, contato dialetal etc.), o que justifica a mudança linguística aí observada.

Ainda nessa tese, compara-se o português com o francês no que se refere ao fenômeno estudado. Para isso, foram analisados também dados diacrônicos do francês extraídos do Banco de Dados do Francês Medieval (Banque du Français Medieval - BFM) e os resultados apontam para o mesmo processo de mudança linguística: decréscimo do futuro simples e implementação do futuro perifrástico formado com o verbo ir + infinitivo (aller + infinitif em francês). 
3.3. A palatalização de /t, $d$ / diante de [i]

As consoantes oclusivas /t, $\mathrm{d} /$ diante de vogal alta [i], como em tio, dia , assim como também em noite, tarde, tẹsoura, desvio - em que o contexto condicionador deriva do alçamento da vogal anterior média, em posição átona -, ora mantêm a articulação oclusiva $[t, d]$, ora passam à articulação africada ou palatalizada [t $5, \mathrm{~d} 3]$.

Retomando os estudos sobre essa variação, Oliveira e Mota (a sair) analisaram sociolinguisticamente dados de 25 capitais brasileiras coletados do Projeto ALiB, considerando, pois, a estratificação dos informantes por sexo, faixa etária e escolaridade, além da variável diatópica e do tipo de registro (mais ou menos monitorado). Como variáveis linguísticas, as autoras controlaram o vozeamento da consoante (/t/ ou /d/), a posição e a tonicidade da sílaba, a vogal e a consoante antecedentes e a nasalidade da vogal [i] subsequente. A análise foi feita em duas rodadas, uma para /t, d/ diante de [i] vogal fonológica (tia, dia) e outra para /t, d/ diante de [i] vogal derivada (noite, tarde, tesoura, desvio).

Os resultados da pesquisa mostram que predomina a realização palatalizada (variante inovadora, já que nunca foi a articulação do português europeu) no território brasileiro ( $68 \%$ diante da vogal [i] fonológica e $66 \%$ diante da vogal [i] derivada), que chega a ser categórica em algumas cidades (Belém, Rio Branco, Fortaleza, Salvador, São Luís, Belo Horizonte, Rio de Janeiro, São Paulo, Vitória, Porto Alegre e Goiânia, sendo que, nesta última a realização categórica acontece apenas diante da vogal [i] fonológica), e que a variação é condicionada diatopicamente, já que a variável 'cidade' foi a primeira selecionada em ambas as rodadas como a mais significativa do ponto de vista estatístico. A realização oclusiva (dental ou dento-alveolar) resiste apenas na costa leste do Nordeste (Natal, João Pessoa, Recife, Maceió e Aracaju), em Cuiabá e em Florianópolis. As autoras atestam ainda que, diante da vogal fonológica, a cidade de Curitiba também mantém a variante conservadora (dental ou dento-alveolar).

Diante da vogal fonológica, favorecem a palatalização a consoante antecedente constritiva palatal (peso relativo 0,73 ) - como em pro[J]tituta -, as sílabas átonas (peso relativo 0,58 ) e faixa etária mais jovem (peso relativo 0,59 ). Diante da vogal derivada, favorecem a palatalização a faixa etária mais jovem (peso relativo 0,62), a semivogal antecedente [y] (peso relativo 0,66), as consoantes antecedentes constritiva palatal (com palatalização categórica) e mesmo a constritiva alveolar (peso relativo 0,72 ) - como em agre [s]te -, o sexo feminino (peso relativo 0,54 ) e o nível de escolaridade mais alto (peso relativo $0,53)$. E as autoras concluem por um processo de mudança em curso, a partir do estudo em tempo aparente, com a implementação da variante palatalizada, considerada de maior prestígio no Brasil.

Cumpre informar que esta pesquisa continua em andamento, estando em análise no momento os dados das cidades do interior do Brasil. 
OLIVEIRA - A sociolinguística laboviana: festejando o cinquentenário e planejando o futuro

\subsection{A variação na expressão do imperativo verbal}

Em pesquisa atual, em desenvolvimento, Oliveira (a sair) retoma o fenômeno variável da expressão do imperativo gramatical no português brasileiro, analisando sociolinguisticamente dados do Projeto ALiB. Essa variação de formas verbais de imperativo (pegue/pega, diga/diz, venha/vem) no português brasileiro é um fenômeno encaixado com a variação entre os modos indicativo e subjuntivo e com a variação entre os pronomes de segunda pessoa tu/você.

A autora, considerando as variáveis sociais 'sexo', 'faixa etária' e 'escolaridade', a variável diatópica 'cidade' (por enquanto, com dados das capitais brasileiras) e as variáveis linguísticas 'polaridade da sentença' (imperativo afirmativo ou negativo), 'extensão fonológica do verbo' (medida em termos de quantidade de sílabas do verbo no infinitivo), 'paradigma verbal' (verbo regular ou irregular, considerando a saliência fônica) e 'presença (próclise ou ênclise) ou ausência de clíticos', constata que predomina a forma de imperativo associada ao indicativo no Brasil ( $65 \%$ dos dados).

As variáveis selecionadas na análise quantitativa foram 'cidade', o que comprova ser essa variação um traço dialetal, 'nível de escolaridade', 'polaridade da sentença', 'paradigma verbal' e 'faixa etária', nesta ordem de significância estatística.

Quanto à variável diatópica, a variante associada à forma de subjuntivo é predominante apenas no Nordeste (com exceção de São Luís), em Porto Velho e em Curitiba.

Quanto às variáveis sociais, a variante associada ao indicativo é favorecida pelos falantes de nível de escolaridade fundamental (peso relativo 0,57) e pelos mais jovens (peso relativo 0,54), o que indica a forte atuação da escola, uma vez que a forma associada ao subjuntivo é a prescrita pela tradição gramatical quando do uso do pronome você de segunda pessoa, que predomina na grande maioria das capitais brasileiras, e uma possível mudança em progresso, já que as formas de imperativo associadas ao subjuntivo são vistas como estigmatizadas por muitos falantes não-nordestinos, chegando mesmo a ser avaliadas como indicador de falta de polidez e de autoritarismo.

Finalmente, quanto às variáveis linguísticas, a forma de imperativo associada ao indicativo (variante considerada inovadora) é implementada em frases afirmativas (peso relativo 0,54 ) e com verbos regulares (peso relativo 0,61 ), que são menos salientes.

Essa pesquisa também está em andamento, com a análise de dados das cidades do interior do Brasil e com a consideração de outras variáveis, como, por exemplo, o enunciado real, hipotético ou reproduzido (a depender da situação apresentada durante a entrevista) e a imediaticidade da ação solicitada (se uma ordem ou um pedido imediato, se um conselho a ser considerado no médio/longo prazo). 
4. UM OLHAR PARA O FUTURO

A partir deste sumário balanço dos estudos sociolinguísticos no Brasil, constata-se que, de fato, muito já foi feito e muito está sendo feito nessa área. A documentação e a análise do português brasileiro (tanto falado como escrito) constituem empreendimentos avançados e de grande sucesso num país de dimensões continentais e de estratificação histórica, social, cultural e econômica bastante diversificada.

O quadro teórico-metodológico estabelecido no SSENYC tem sido largamente utilizado pelos linguistas brasileiros e muito já se sabe sobre a realidade sociolinguística do País.

Considerando, todavia, que as línguas variam e mudam constantemente e que a ciência também se renova, sobretudo em se tratando de uma teoria baseada no uso - e os usos linguísticos são, por natureza, inovadores, originais e variáveis -, muito ainda precisa ser feito. Se o objeto de estudo da área é a língua, que se renova incessantemente, sempre o terreno se apresenta fértil para (re)análises. A sociolinguística, pois, como ciência humana, nunca se esgota; sempre haverá novos dados, novos métodos e novos olhares.

Com essa concepção, é possível (re)pensar e até mesmo planejar uma agenda de trabalhos na área da Sociolinguística para os próximos cinquenta anos. Afinal, são muitos os mestres e doutores na área que recebem seus diplomas anualmente no Brasil e que, portanto, devem se engajar nos variados núcleos/grupos e projetos de pesquisa.

Levando em conta a interdependência entre os componentes linguísticos (fonético, fonológico, morfológico, sintático e lexical), a interdependência entre estes e outros componentes da linguagem (o discurso, o texto, a pragmática) e a interdependência entre os componentes linguísticos e os extralinguísticos (social, histórico, cultural, cognitivo e interacional), necessariamente, é preciso que os trabalhos sejam cada vez mais interdisciplinares. Daí a urgência de mais grupos de pesquisa e de associações em rede e de menos pesquisas individuais.

A partir do passeio que se fez pelos últimos cinquenta anos, percebe-se que as análises têm fornecido elementos para a discussão de questões teóricas - 0 que deve constar sempre da pauta - e para um mapeamento da língua portuguesa no Brasil. É necessário, pois, investir mais em estudos que comparem as muitas variedades descritas, como apresentam, por exemplo, os capítulos reunidos em Martins e Abraçado (2015), nos quais se comentam resultados de vários estudos realizados no âmbito da sociolinguística brasileira.

Alguns dos caminhos a serem percorridos (aliás, já iniciados) são: a conjugação de estudos macrossociolinguísticos, que consideram categorias linguísticas e sociais mais amplas, e microssociolinguísticos, que se debruçam sobre variáveis mais específicas, como, por exemplo as interacionais (BORTONIRICARDO 2014:37-47); a conjunção de estudos sincrônicos (que predominam na sociolinguística brasileira) com estudos diacrônicos (estes em menor número); a realização de mais trabalhos sobre percepção, atitudes e crenças em relação à variação e à mudança linguísticas; a descrição de línguas minoritárias, que 
sobrevivem historicamente no Brasil; a investigação de comunidades de práticas, com ênfase na análise dos estilos (trabalhos mais conhecidos como de terceira onda); a consideração da dimensão diatópica ao lado da social, tendo em vista que muitas variáveis sociais atuam diferentemente no imenso espaço geográfico brasileiro; a realização de estudos de comparação de línguas; o diálogo com outras áreas/ ciências, tais como o Texto, o Discurso, a Pragmática, o Funcionalismo, a Cognição, a Aquisição da Linguagem, o Gerativismo, o Contato Linguístico, a Dialetologia, a Política Linguística, os Estudos Culturais, os Estudos sobre Gênero, o Ensino de L1 e de L2, o Bilinguismo e o Multilinguismo, a Linguística Aplicada, a Psicologia, a Sociologia, a História, a Linguística de Corpus, a Computação, a Estatística; a revisão dos procedimentos e métodos de coleta de dados, com ênfase no tratamento da variação estilística (GÖRSKI; COELHO; SOUZA 2014); o investimento em novas ferramentas de suporte estatístico para a análise de variáveis contínuas, do léxico, da interação (RBrul, R) e da variação eneária; entre outros.

Enfim, retomando as palavras de Mollica e Roncarati (2001), que resumem bem uma proposição de agenda de trabalho,

As questões de maior saliência que devem compor a agenda de trabalho voltam-se para: (a) exame da tensão entre fatores sociais e funcionais; (b) reflexão sobre a natureza da variação; (c) proposição de universais sociolinguísticos numa perspectiva comparativista inter- e intralinguística; (d) aquisição da contraparte variável da língua em comunidades monolíngues, bilíngues e plurilíngues e (d) inter-relações entre variacionismo, geografia dialetal, funcionalismo e gerativismo.

É natural que se dê continuidade ao desenvolvimento de análises de fenômenos linguísticos variáveis que possam favorecer a interação entre os grupos de pesquisa no Brasil, visando, de um lado, mapear a variação linguística no território nacional e, de outro, participar da discussão teórica internacional sobre a relação entre variação e mudança linguística, variação e mudança de código e variação inerente e gramáticas em competição. (MOLLICA; RONCARATI 2001:50)

Ou seja, muito já se fez, mas ainda há sempre e muito o que fazer quando se toma como objeto de pesquisa a linguagem humana.

\section{CONCLUSÕES}

Buscou-se neste artigo festejar o cinquentenário da tese laboviana SSENYC com uma visão semelhante à do deus Jano, lançando um olhar para o passado e para o futuro, passeando pelo presente, com os objetivos de fazer um breve relato dos frutos dessa obra no Brasil e de propor uma agenda de tarefas a serem realizadas nos próximos cinquenta anos.

Apresentando os primeiros trabalhos (dissertações de Mestrado e teses de Doutorado) desenvolvidos no Brasil, relatando alguns que a esses se seguiram, evidenciaram-se os principais temas investigados em análises que adotaram os princípios teórico-metodológicos da Sociolinguística e mencionaram-se os principais projetos executados por grupos de pesquisa nesse campo, além de terem sido destacados alguns dos eventos promovidos na área, que possibilitam produtiva discussão de questões científicas e trocas de experiências entre os envolvidos. 
A seguir, exemplificou-se a aplicação da proposta do mestre norteamericano com um sumário de pesquisas autorais desenvolvidas e em desenvolvimento com o intuito de ratificar a fertilidade dessa área e a sua importância para a descrição, a análise e o mapeamento da língua portuguesa, em suas várias normas, no País.

A partir desse balanço, levantaram-se questões a serem aprofundadas e foram sugeridos caminhos ainda a serem mais explorados, evidenciando que os estudos sobre variação e mudança linguística abrem um leque interdisciplinar que em muito pode auxiliar os pesquisadores que se debruçam sobre o entendimento do funcionamento da linguagem humana, concebida como produto de interação social, histórica e cultural.

Espera-se, assim, a partir do resgate de um pouco da história da área no Brasil e da projeção de tarefas bem-vindas, não só fornecer ao leitor referências básicas a partir das quais se pode descobrir um mundo vasto de pesquisas mas também estimulá-lo a integrar a rede de profissionais e estudantes que se engajam no trabalho incessante e inesgotável de desvendar o mistério instigante que é a língua.

\section{REFERÊNCIAS}

ALMEIDA, Evanilda Marins (2010) Uso e norma: variação da concordância verbal em redações escolares. Rio de Janeiro: UFRJ (Tese de Doutorado).

ALMEIDA, Fernanda dos Santos (2015) A expressão variável do futuro verbal no discurso político em três cidades baianas: Salvador, Feira de Santana e Vitória da Conquista. Feira de Santana: UEFS (Dissertação de Mestrado).

ALMEIDA, Gilce de Souza (2014) Uso variável dos pronomes-objeto na expressão do dativo $e$ do acusativo de segunda pessoa em Santo Antônio de Jesus. Salvador: UFBA (Tese de Doutorado).

ALMEIDA, Jussara (1998) Ordem no português de contato e no português vernacular. Rio de Janeiro: UFRJ (Tese de Doutorado).

ALMEIDA SANTOS, Patrícia Tavares (2008) Só um instante, senhora, que eu vou tá verificando se o livro tá disponível na editora: gerundismo, preconceito e a expansão da mudança. Brasília: UnB (Dissertação de Mestrado).

ALVES, Thiago Gil Lessa (2011) A expressão da futuridade nos tipos de discurso do expor e do narrar a partir de textos de lingua falada e escrita cearenses. Fortaleza: UFC (Tese de Doutorado).

AMARAL, Eduardo Tadeu Roque (2003) A ausência/presença de artigo definido diante de antropônimos em três localidades de Minas Gerais: Campanha, Minas Novas e Paracatu. Belo Horizonte: UFMG (Dissertação de Mestrado).

AMARAL, Luís I. C. (2003) A concordância verbal de segunda pessoa do singular em Pelotas e suas implicações linguísticas e sociais. Porto Alegre: UFRGS (Tese de Doutorado).

ANDRADE, Carolina Queiroz (2010) Tu e mais quantos? A segunda pessoa na fala brasiliense. Brasília: UnB (Dissertação de Mestrado). 
OLIVEIRA - A sociolinguística laboviana: festejando o cinquentenário e planejando o futuro

ANDRADE, Elton Jones Barbosa (2008) Palatalização das oclusivas dentais/t/e /d/na fala pessoense. João Pessoa: UFPB (Dissertação de Mestrado).

ANDRADE NETA, Antônia Verônica (2003) Alternância seu/dele no falar pessoense. João Pessoa: UFPB (Dissertação de Mestrado).

ARAÚJO, Silvana Silva de Farias (2014) A concordância verbal no português falado em Feira de Santana-BA: sociolinguística e sócio-história do português brasileiro. Salvador: UFBA (Tese de Doutorado).

ARDUIN, Joana (2005) A variação dos pronomes possessivos de segunda pessoa do singular teu/seu na região Sul do Brasil. Florianópolis: UFSC (Dissertação de Mestrado).

ASSUNÇÃO, Janivam da Silva (2012) A indeterminação do sujeito na variedade linguística de Feira de Santana: um estudo variacionista. Feira de Santana: UEFS (Dissertação de Mestrado).

BARBOSA, Astrid Franco (2011) Alternância de formas indicativas e subjuntivas na fala de Vitória$E S$. Vitória: UFES (Dissertação de Mestrado).

BARBOSA, Tatiane Alves Maciel (2005) A variação entre futuro do pretérito e pretérito imperfeito do indicativo em orações condicionais iniciadas por "se" na fala uberlandense. Uberlândia: UFU (Dissertação de Mestrado).

BATISTA, Eliete Figueira (1996) $O$ uso de artigo diante de pronomes possessivos na fala de comunidades rurais do Estado do Rio de Janeiro. Rio de Janeiro: UFRJ (Dissertação de Mestrado).

BISOL, Leda (1981) Harmonização vocálica: uma regra variável. Rio de Janeiro: UFRJ (Tese de Doutorado).

BORTONI-RICARDO, Stella Maris (2014) Manual de sociolinguística. São Paulo: Contexto.

BRAGA, Maria Luiza (1977) A concordância de número no sintagma nominal no triângulo mineiro. Rio de Janeiro: PUC (Dissertação de Mestrado).

BRAGANÇA, Marcela Langa L. (2008) A gramaticalização do verbo ir e a variação de formas para expressar o futuro do presente: uma fotografia capixaba. Vitória: Universidade Federal do Espírito Santo (Dissertação de Mestrado).

CABREIRA, Sílvio Henrique (1996) A monotongação dos ditongos orais decrescentes em Curitiba, Florianópolis e Porto Alegre. Porto Alegre: PUC (Dissertação de Mestrado).

CALLOU, Dinah M. I. (1979) Variação e distribuição da vibrante na fala culta do Rio de Janeiro. Rio de Janeiro: UFRJ (Tese de Doutorado).

CARDOSO, Caroline Rodrigues (2005) Variação da concordância verbal no indivíduo: um confronto entre o linguístico e o estilístico. Brasília: UnB (Dissertação de Mestrado).

CARDOSO, Daisy Barbosa Borges (2009) Variação e mudança no imperativo do português brasileiro: gênero e identidade. Brasília: UnB (Tese de Doutorado).

CARDOSO, Suzana Alice M.; MOTA, Jacyra A.; AGUILERA, Vanderci A.; ARAGÃO, Maria do Socorro S.; ISQUERDO, Aparecida N.; RASKY, Abdelhak; MARGOTTI, Felício W.; 
ALTENHOFEN, Cléo V. (2014a) Atlas linguístico do Brasil, v. 1 (Introdução). Londrina: EDUEL.

CARDOSO, Suzana Alice M.; MOTA, Jacyra A.; AGUILERA, Vanderci A.; ARAGÃO, Maria do Socorro S.; ISQUERDO, Aparecida N.; RASKY, Abdelhak; MARGOTTI, Felício W. (2014b) Atlas linguístico do Brasil, v. 2 (Cartas Linguísticas 1). Londrina: EDUEL.

CARNEIRO, Honorina M. S. (2011) As formas de tratamento tu/você no português falado ludovicense. Araraquara: UNESP (Tese de Doutorado).

CARVALHO, Hebe M. (2007) A alternância indicativo/subjuntivo em orações substantivas em função dos tempos verbais presente e imperfeito na língua falada do Cariri. Fortaleza: UFC (Tese de Doutorado).

CARVALHO, Sérgio D. M. (2002) A palatalização das plosivas dentais na fala de pescadores do Norte e Noroeste do Estado do Rio de Janeiro. Rio de Janeiro: UFRJ (Dissertação de Mestrado).

COSTA, Ana Lúcia P. (1997) A variação entre formas de futuro do pretérito e de pretérito imperfeito no português informal no Rio de Janeiro. Rio de Janeiro: UFRJ (Dissertação de Mestrado).

COSTA, Ana Lúcia P. (2003) O futuro do pretérito e suas variantes no português do Rio de Janeiro: um estudo diacrônico. Rio de Janeiro: UFRJ (Tese de Doutorado).

CUNHA, Cláudia S. (1993) Indeterminação pronominal do sujeito. Rio de Janeiro: UFRJ (Dissertação de Mestrado).

DEL-GÁUDIO, Sandra M. A. (1981) Emprego e colocação variável dos pronomes pessoais e oblíquos átonos no português do Brasil. Rio de Janeiro: PUC (Dissertação de Mestrado).

EVANGELISTA, Elaine M. (2009) Fala, Vitória! - A variação do imperativo na cidade de Vitória-ES e sua posição no cenário nacional. Vitória: UFES (Dissertação de Mestrado).

FELGUEIRAS, Carmen (1993) M. Análise da variação no uso da preposição para. Rio de Janeiro: UFRJ (Dissertação de Mestrado).

FERNANDES, Eliene A. (1997) Nós, a gente: variação em João Pessoa. João Pessoa: UFPB (Dissertação de Mestrado).

FERREIRA, Débora C. L. (2002) O tratamento das formas pronominais alternantes nós e a gente na escrita. Rio de Janeiro: UFRJ (Dissertação de Mestrado).

FIGUEIREDO SILVA, Maria Cristina. (2004) O objeto direto anafórico no dialeto rural afrobrasileiro. Salvador: UFBA (Dissertação de Mestrado).

FIGUEREIDO, Joana G. S. (2015) A expressão do futuro verbal na escrita escolar de Irará-BA. Feira de Santana: UEFS (Dissertação de Mestrado).

FIORETTI, Maria Thereza G. (1996) A alternância no uso dos verbos existenciais em português. Rio de Janeiro: UFRJ (Dissertação de Mestrado).

FRANCESCHINI, Lucelene Teresinha (2011) Variação pronominal nós/a gente e tu/você em Concórdia-SC. Curitiba: UFPR (Tese de Doutorado). 
OLIVEIRA - A sociolinguística laboviana: festejando o cinquentenário e planejando o futuro

FREITAG, Raquel M. K. (2007) A expressão do passado imperfectivo no português: variação/ gramaticalização e mudança. Florianópolis: UFSC (Tese de Doutorado).

GIBBON, Adriana O. (2000) A expressão do tempo futuro na língua falada de Florianópolis: gramaticalização e variação. Florianópolis: UFSC (Dissertação de Mestrado).

GODOY, Maria Alice M. (1999) A indeterminação do sujeito no interior paranaense: uma abordagem sociolinguística. Curitiba: UFPR (Dissertação de Mestrado).

GOMES, Christina A. (1996) Aquisição e perda de preposições. Rio de Janeiro: UFRJ (Tese de Doutorado).

GÖRSKI, Edair M.; COELHO, Izete L.; SOUZA, Christiane M. N. (Org.) (2014) Variação estilística: reflexões teórico-metodológicas e propostas de análise. Florianópolis: Insular.

GRYNER, Helena (1990) A variação de tempo-modo e conexão nas orações condicionais em português. Rio de Janeiro: UFRJ (Tese de Doutorado).

HORA, Dermeval (1990) A palatalização de oclusivas dentais: variação e representação não-linear. Porto Alegre: PUC (Tese de Doutorado).

JESUS, Elton T. (2006) O estereótipo na mídia e os estereótipos linguísticos: estudo do imperativo na novela Senhora do Destino. Brasília: UnB (Dissertação de Mestrado).

KAILER, Dircel A. (2008) Vogais pretônicas /e/ e /o/: um estudo em tempo aparente. Araraquara: UNESP (Tese de Doutorado).

LABOV, William (1966) The social stratification of English in New York. New York: Center for Applied Linguistics.

LABOV, William (1972) Sociolinguistics patterns. Philadelphia: University of Pennsylvania Press.

LABOV, William (1994) Principles of linguistic change (internal factors), v. 1. Oxford: Blackwell.

LABOV, William (2001) Principles of linguistic change (social factors), v. 2. Oxford: Blackwell.

LABOV, William (2010) Principles of linguistic change (cognitive and cultural factors), v. 3. Oxford: Wiley-Blackwell.

LADEIRA, José Dionísio (1986) A flexão do infinitivo em português. Rio de Janeiro: UFRJ (Tese de Doutorado).

LIMA, Damaris S. P. (2005) A expressão do imperativo na fala de Campo Grande. Brasília: UnB (Dissertação de Mestrado).

LOPES, Raquel (2002) A realização variável dos ditongos [ow] e [ej] no português falado em Altamira-PA. Belém: UFPA (Dissertação de Mestrado).

LUCCA, Nívia Naves G. (2005) A variação tu/você na fala brasiliense. Brasília: UnB (Dissertação de Mestrado).

LUCCHESI, Dante (2000) A variação na concordância de gênero em uma comunidade de fala afrobrasileira: novos elementos sobre a formação do português popular do Brasil. Rio de Janeiro: UFRJ (Tese de Doutorado). 
LUCENA, Rubens M. (2001) Comportamento sociolinguístico da preposição para na fala da Paraíba. João Pessoa: UFPB (Dissertação de Mestrado).

LUCENA, Rachel de Oliveira P. (2016) Pronomes possessivos de segunda pessoa: a variação teu/seu em uma perspectiva histórica. Rio de Janeiro: UFRJ (Tese de Doutorado).

MACEDO, Alzira V. T. (1981) Uso do futuro do subjuntivo em português: regularização de uma forma verbal. Rio de Janeiro: UFRJ (Tese de Doutorado).

MACEDO, Sandra S. (2004) A palatalização do /s/ em coda silábica no falar culto recifense. Recife: UFPE (Dissertação de Mestrado).

MACHADO, Ana Carla M. (2006) O uso e a ordem dos clíticos na escrita de estudantes da cidade do Rio de Janeiro. Rio de Janeiro: UFRJ (Dissertação de Mestrado).

MALVAR, Elisabete S. (1992) A realização do objeto direto de $3^{a}$ pessoa em cadeia anafórica no português do Brasil. Brasília: UnB (Dissertação de Mestrado).

MALVAR, Elisabete S. (2003) Future temporal reference in Brazilian Portuguese: past and present. Ottawa: Universidade de Ottawa (Tese de Doutorado).

MARAFONI, Renata L. (2004) A realização do objeto direto anafórico: um estudo em tempo real de curta duração. Rio de Janeiro: UFRJ (Dissertação de Mestrado).

MARAFONI, Renata L. (2010) A distribuição do objeto nulo no português europeu e no português brasileiro. Rio de Janeiro: UFRJ (Tese de Doutorado).

MARTINS, Marco Antônio; ABRAÇADO, Jussara (Org.) (2015) Mapeamento sociolinguístico do português brasileiro. São Paulo: Contexto.

MARTINS, Germano F. (2010) A alternância tu / você / senhor no município de Tefé, Estado do Amazonas. Brasília: UnB (Dissertação de Mestrado).

MARTINS, Mariana S. (2008) Palatalização de oclusivas dentais em contato dialetal. Rio de Janeiro: UFRJ (Dissertação de Mestrado).

MENDONÇA, Valdenice A. (2002) A língua falada na cidade de Mata Grande: a variação do objeto direto. Maceió: UFAL (Dissertação de Mestrado).

MENON, Odete Pereira S. (1994) Analyse sociolinguistique de l'indetermination du sujet dans le portugais parlé au Brésil à partir des données du NURC-SP. Paris: Université de Paris VII (Tese de Doutorado).

MOLLICA, Maria Cecília M. (1977) Estudo da cópia nas construções relativas em português. Rio de Janeiro: PUC (Dissertação de Mestrado).

MOLLICA, Maria Cecília M. (1989) Queísmo e dequeísmo no português do Brasil. Rio de Janeiro: UFRJ (Tese de Doutorado).

MOLLICA, Maria Cecília M.; RONCARATI, Cláudia N. (2001) Questões teórico-descritivas em sociolinguística e em sociolinguística aplicada e uma proposta de agenda de trabalho. D.E.L.T.A., São Paulo, v. 17, n. especial, p. 45-55. Disponível em: http://www.scielo.br/scielo.php?script=sci_ arttext\&pid=S0102-44502001000300004\&lng=en\&nrm=iso. Acesso em: 14 out. 2016.

MONGUILHOTT, Isabel O. S. (2009) Estudo sincrônico e diacrônico da concordância verbal de terceira pessoa do plural no PB e no PE. Florianópolis: UFSC (Tese de Doutorado). 
OLIVEIRA - A sociolinguística laboviana: festejando o cinquentenário e planejando o futuro

MONTALVO, Solange M. (1978) Derivação sufixal e variação. Rio de Janeiro: PUC (Dissertação de Mestrado).

MOURA, Adriano C. (2009) O comportamento da lateral pós-vocálica em posição de coda no falar tocantinense: uma análise variacionista. João Pessoa: UFPB (Dissertação de Mestrado).

NASCIMENTO, Rodrigo A. C. (2008) Zero ou um: uso do artigo indefinido diante de nomes incontáveis. Rio de Janeiro: UFRJ (Dissertação de Mestrado).

NAZÁRIO, Maria de Lurdes (2007) Uso variável do artigo definido diante de pronome possessivo na variedade linguística da comunidade de fala dos Almeidas. Goiânia: UFG (Dissertação de Mestrado).

OLIVEIRA, Gilvando A. (2001) $O$ /s/ implosivo na cidade de Natal: uma visão variacionista. João Pessoa: UFPB (Dissertação de Mestrado).

OLIVEIRA, Josane M. (1999) O apagamento do /R/ implosivo na norma culta de Salvador. Salvador: UFBA (Dissertação de Mestrado).

OLIVEIRA, Josane M. (2006) O futuro da língua portuguesa ontem e hoje: variação e mudança. Rio de Janeiro: UFRJ (Tese de Doutorado).

OLIVEIRA, Josane M.; MOTA, Jacyra A. As consoantes oclusivas /t, d/ diante de [i] nas capitais brasileiras. Capítulo a sair no volume 3 do Atlas Linguístico do Brasil, a ser publicado pela Editora da Universidade Estadual de Londrina.

OLIVEIRA E SILVA, Gisele M. (1983) Estudo da regularidade na variação dos possessivos no português do Rio de Janeiro. Rio de Janeiro: UFRJ (Tese de Doutorado).

OMENA, Nelize P. (1978) Pronome pessoal de terceira pessoa: suas formas variantes em função acusativa. Rio de Janeiro: PUC 1978 (Dissertação de Mestrado).

OUSHIRO, Livia (2011) Uma análise variacionista para as Interrogativas-Q. São Paulo: USP (Dissertação de Mestrado).

OUSHIRO, Livia (2015) Identidade na pluralidade: avaliação, produção e percepção linguística na cidade de São Paulo. São Paulo: USP (Tese de Doutorado).

PAIVA, M. C.; DUARTE, M. E. L. (2006) Quarenta anos depois: a herança de um programa na sociolinguística brasileira. In: WEINREICH, U.; LABOV, W.; HERZOG, M. I. Fundamentos empíricos para uma teoria da mudança linguística. Trad. de Marcos Bagno e Carlos Alberto Faraco. São Paulo: Parábola, p. 131-151.

PAIVA, M. C.; SCHERRE, M. M. P. (1999) Retrospectiva sociolinguística: contribuições do PEUL. D.E.L.T.A., v. 15, n. especial, São Paulo, p. 201-232. Disponível em: http://www.scielo.br/ scielo.php?script $=$ sci_arttext\&pid=S0102-44501999000300009\&lng=en\& $\mathrm{nrm}=\mathrm{iso}$. Acesso em: 27 out. 2016.

PALMA, Maria Luiza C. (1980) Variação fonológica na fala de Mato Grosso: um estudo sociolinguístico. Rio de Janeiro: PUC (Dissertação de Mestrado).

PAREDES SILVA, Vera Lúcia (1988) Cartas cariocas: a variação do sujeito na escrita informal. Rio de Janeiro: UFRJ (Tese de Doutorado).

PEREIRA, Maria das Graças D. (1981) A variação na colocação dos pronomes átonos no português do Brasil. Rio de Janeiro: PUC (Dissertação de Mestrado). 
$\overline{\text { PEREIRA, Regina C. M. (1997) Estudo das vogais pretônicas na fala pessoense urbana. João Pessoa: }}$ UFPB (Dissertação de Mestrado).

PIMPÃO, Tatiana S. (2012) Uso variável do presente no modo subjuntivo: uma análise de amostras de fala e escrita das cidades de Florianópolis e Lages nos séculos XIX e XX. Florianópolis: UFSC (Tese de Doutorado).

PINTO, Ivone I. (1996) A variação entre tudo e todo(a)(s) no português informal carioca. Rio de Janeiro: UFRJ (Dissertação de Mestrado).

RAMOS, Fabiana (1999) Atitudes linguísticas de falantes campinenses sobre os fenômenos da palatalização das consoantes /t/ e /d/ e do uso da concordância nominal de número. João Pessoa: UFPB (Dissertação de Mestrado).

RAMOS, M. P. B. (1989) Formas de tratamento no falar de Florianópolis. Florianópolis: UFSC (Dissertação de Mestrado).

RIBEIRO, Antônio João C. (1996) Um caso variável de preposições na chamada fala culta carioca: a regência do verbo ir de predicação. Rio de Janeiro: UFRJ (Dissertação de Mestrado).

RIBEIRO, Silvia Renata (2006) Apagamento da sibilante final em lexemas: uma análise variacionista do falar pessoense. João Pessoa: UFPB (Dissertação de Mestrado).

ROCHA, Patrícia Graciela (2012) O sistema de tratamento do português de Florianópolis: um estudo sincrônico. Florianópolis: UFSC (Tese de Doutorado).

ROCHA, Rosa Cecília F. (1997) A alternância indicativo/subjuntivo nas orações subordinadas substantivas em português. Brasília: UnB (Dissertação de Mestrado).

RODRIGUES, Ângela C. S. (1988) A concordância verbal no português popular em São Paulo. São Paulo: USP (Tese de Doutorado).

RODRIGUES, Sandra Helena A. (2001) O /s/ pós-vocálico na fala da região Norte-Noroeste do Estado do Rio de Janeiro. Rio de Janeiro: UFRJ (Dissertação de Mestrado).

ROST-SNICHELOTTO, Cláudia Andréa (2009) Olha e vê: caminhos que se entrecruzam. Florianópolis: UFSC (Tese de Doutorado).

RUBIO, Cássio F. (2012) Padrões de concordância verbal e de alternância pronominal no português brasileiro e europeu: estudo sociolinguístico comparativo. São José do Rio Preto: UNESP (Tese de Doutorado).

SÁ, Edmilson J. (2007) Variação do /l/ em coda silábica na fala. João Pessoa: UFPB (Dissertação de Mestrado).

SALOMÃO, A. C. B. (2011) Variação e mudança linguística: panorama e perspectivas da sociolinguística variacionista no Brasil. Fórum Linguístico, v. 8, n. 2, Florianópolis, jul.-dez., p. 187-207. Disponível em: https://periodicos.ufsc.br/index.php/forum/article/view/19848412.2011v8n2p187/21673. Acesso em: 27 out. 2016.

SAMPAIO, Dilcélia A. (2001) Modo imperativo: sua manifestação/expressão no português contemporâneo. Salvador: UFBA (Dissertação de Mestrado).

SANTOS, Adriana M. (1997) O futuro verbal no português do Brasil em variação. Brasília: UnB (Dissertação de Mestrado). 
OLIVEIRA - A sociolinguística laboviana: festejando o cinquentenário e planejando o futuro

SANTOS, Alessandra de Paula (2010) Vogais médias postônicas não-finais na fala do Estado do Rio de Janeiro. Rio de Janeiro: UFRJ (Dissertação de Mestrado).

SANTOS, Aline Silva (2014) A variação entre o futuro do pretérito e o pretérito imperfeito no português falado em Feira de Santana. Feira de Santana: UEFS (Dissertação de Mestrado).

SANTOS, Eduardo P. (2012) A expressão da futuridade verbal em Santo Antônio de Jesus: uma análise variacionista. Salvador: UNEB (Dissertação de Mestrado).

SANTOS, Gredson (2012) O português afro-brasileiro de Helvécia-BA: análise da variável -S em coda silábica. Salvador: UFBA (Tese de Doutorado).

SANTOS, Josete R. (2000) A variação entre as formas de futuro do presente no português formal e informal falado no Rio de Janeiro. Rio de Janeiro: UFRJ (Dissertação de Mestrado).

SARAIVA, Carlos Alberto M. (2001) As múltiplas realizações do fonema $/ \mathrm{s} /$ em posição de coda na fala do cratense. João Pessoa: UFPB (Dissertação de Mestrado).

SCHERRE, Maria Marta Pereira (1978) A regra de concordância de número no sintagma nominal em português. Rio de Janeiro: PUC (Dissertação de Mestrado).

SCHERRE, Maria Marta Pereira (1988) Reanálise da concordância nominal em português. Rio de Janeiro: UFRJ (Tese de Doutorado).

SETTI, Adriane Cristina R. (1997) A indeterminação do sujeito nas três capitais do Sul do Brasil. Curitiba: UFPR (Dissertação de Mestrado).

SILVA, Ailma N. (2009) As pretônicas no falar teresinense. Porto Alegre: PUC (Tese de Doutorado).

SILVA, Fabiana S. (1997) Processo de monotongação em João Pessoa. João Pessoa: UFPB (Dissertação de Mestrado).

SILVA, Jorge Augusto A. (2005) A concordância verbal de terceira pessoa do plural no português popular do Brasil: um panorama sociolinguístico de três comunidades do interior do Estado da Bahia. Salvador: UFBA (Tese de Doutorado).

SILVA, Myrian B. (1989) As pretônicas no falar baiano: a variedade culta de Salvador. Rio de Janeiro: UFRJ (Tese de Doutorado).

SILVA, Márcia D. L. (2008) Atitudes linguísticas: um estudo sobre as variantes de objeto direto anafórico. Rio de Janeiro: UFRJ (Tese de Doutorado).

SILVA, Rita do Carmo P. (2010) A representação do tempo futuro em textos escritos: análises em tempo real de curta e de longa duração. Curitiba: UFPR (Tese de Doutorado).

SILVA, Silvania Oliveira (2005) A concordância verbal em redações de vestibular. Brasília: UnB (Dissertação de Mestrado).

SOARES, Adriana S. (2004) As pretônicas médias em comunidades rurais do semiárido baiano. Salvador: UFBA (Dissertação de Mestrado).

SOARES, Viviane R. (2009) A negação no contato entre dialetos. Rio de Janeiro: UFRJ (Dissertação de Mestrado).

SOUZA, Emerson S. (2015) A preposição 'ni' no continuum rural-urbano de comunidades baianas. Feira de Santana: UEFS (Dissertação de Mestrado). 
$\overline{\text { SOUZA, Soliane S. (2014) Formas pronominais de indeterminação do sujeito: uma comparação }}$ entre as comunidades rurais Matinha e Casinhas (BA). Feira de Santana: UEFS (Dissertação de Mestrado).

SPANÓ, Maria (2008) A ordem verbo-sujeito no português brasileiro e europeu: um estudo sincrônico da escrita padrão. Rio de Janeiro: UFRJ (Tese de Doutorado).

TAMBA, Nahete A. M. (2010) A preposição para e suas variantes no falar araguatinense. João Pessoa: UFPB (Dissertação de Mestrado).

TESCH, Leila Maria (2011) A expressão do tempo futuro no uso capixaba: variação e gramaticalização. Rio de Janeiro: UFRJ (Tese de Doutorado).

VALHO, Mário Anastácio G. (2003) A regência variável do verbo ir de movimento na fala pessoense. João Pessoa: UFPB (Dissertação de Mestrado).

VIANNA, Juliana B. S. (2011) Semelhanças e diferenças na implementação de a gente em variedades do português. Rio de Janeiro: UFRJ (Tese de Doutorado).

VIEGAS, Maria C. (1987) Alçamento das vogais médias pretônicas: uma abordagem sociolinguística. Belo Horizonte: UFMG (Dissertação de Mestrado).

VIEIRA, Sílvia Rodrigues (2002) Colocação pronominal nas variedades brasileira, europeia e moçambicana: a definição da natureza do clítico em três variedades do português. Rio de Janeiro: UFRJ (Tese de Doutorado).

VOGELEY, Ana Carla E. (2011) Vogais médias pretônicas: aquisição e variação. João Pessoa: UFPB (Tese de Doutorado).

VOTRE, Sebastião J. (1978) Aspectos da variação fonológica na fala do Rio de Janeiro. Rio de Janeiro: PUC (Tese de Doutorado).

VOTRE, Sebastião J.; RONCARATI, Cláudia. (Org.). (2008) Anthony Julius Naro e a linguística no Brasil: uma homenagem acadêmica. Rio de Janeiro: 7Letras, FAPERJ.

YACOVENCO, Lilian C. (1993) As vogais médias pretônicas no falar culto carioca. Rio de Janeiro: UFRJ (Dissertação de Mestrado). 